\title{
BEBERAPA JENIS CUCUT BOTOL (Squalidae) YANG TERTANGKAP PANCING RAWAI DASAR DI PERAIRAN SAMUDERA HINDIA DAN ASPEK BIOLOGINYA
}

\author{
Dharmadi ${ }^{*}$ \\ "Peneliti pada Pusat Riset Perikanan Tangkap. Ancol-Jakarta
}

\begin{abstract}
ABSTRAK
Terdapat 9 jenis cucut botol yang tertangkap dengan pancing rawai dasar di perairan Samudera Hindia yaitu Squalus sp.1; Squalus sp. 1b; Squalus sp.2; Squalus sp.2b; Squalus sp. 2c; Squalus sp. 3. Squalus 3b Squalus sp.4: dan Squalus sp.4b. Nisbah kelamin cucut botol jantan dan betina $3565 \%$. Sedangkan tingkat kematangan kelamin jantan cucut botol yang dijumpa dibedakan menjadi 3 kategorı yaitu klasper yang belum berisi atau belum mengandung kapur (not calsification), klasper yang telah berisı sebagian zat kapur (not full calsification), dan klasper yang telah penuh berisi zat kapur (full calsification). Kondisi klasper cucut botol selama pengamatan sebagian besar adalah klasper yang telah penuh berisı zat kapur (full calcification) yang dijumpai pada sekitar bulan Juni.
\end{abstract}

KATA KUNCI: cucut botol, pancing rawai dasar, aspek biologi, Samudera Hindia

\section{PENDAHULUAN}

Cucut botol (dogfish shark) termasuk dalam famili Squalidae yang terdiri atas 3 famili yaitu Echinorhinidae (Bramble sharks), Oxynotidae (Rough sharks), dan Squalidae (Dogfish sharks) (Compagno, 1984). Ordo Squaliformes diperkirakan terdiri atas lebih dari 87 spesies atau sekitar $23 \%$ dari 8 ordo lainnya (Compagno, 1990).

Cucut botol merupakan satu dari beberapa jenis ikan yang mempunyai nilai ekonomis tinggi terutama minyak hati, berukuran antara 50 sampai dengan 70 $\mathrm{cm}$, dan beberapa jenis dapat mencapai $200 \mathrm{~cm}$. Sebagian dari mereka hidup soliter atau memisahkan diri dari kelompok jenis cucut lain. Famili Squalidae berreproduksi secara ovovivipar artinya dengan cara melahirkan individu baru yang telah berkembang dalam kandungan induk betina. Makanan selain memangsa jenis cucut lain juga memangsa hewan Cephalopoda, Crustasea, dan invertebrate lain bahkan mamalia laut (Compagno, 1984).

Hasil tangkapan cucut botol dari perairan Samudera Hindia yang didaratkan di tempat pendaratan ikan di Cilacap, Kedonganan-Bali, dan Tanjung Luar-Lombok Timur berukuran panjang total antara 50 sampai dengan $100 \mathrm{~cm}$. Menurut Castro et al. (1999) di dunia terdapat 42 jenis cucut botol yang tidak boleh dieksploitasi, dan sekitar 43 jenis lain termasuk dalam kategori hampir punah. Di perairan Indonesia jenis cucut botol yang baru tertangkap dan berhasil diidentifikasi sekitar 9 jenis yaitu Squalus sp.1, Squalus sp.1b, Squalus sp.2, Squalus sp.2b. Squalus sp.2c, Squalus sp.3, Squalus sp.3b, Squalus sp.4, dan Squalus sp.4b (Anonim, 2003). Spesies tersebut merupakan spesies dominan yang tertangkap dengan rawai dasar dan jaring dasar di Cilacap (Dharmadi \& Fahmi, 2003). Di KedongananBali dan di Tanjung Luar-Lombok Timur diduga jumlah spesies tersebut terus bertambah, namun kemungkinan populasi makin lama akan makin menurun seiring dengan bertambah jumlah nelayan yang menangkap cucut botol akibat semakin meningkat permintaan komoditas tersebut, terutama nati yang dapat menghasilkan minyak. Seperti sifat jenis cucut lain, cucut botol memiliki umur panjang dengan pertumbuhan relatif lambat (Ketchen, 1975) Oleh karena itu, spesies ini juga rentan terhadap kepunahan akibat ekploitasi yang kurang terkendali. Widodo (2002) mengatakan bahwa tingkat pemanfaatan sumber daya cucut di perairan Indonesia terutama di Lautan Hindia, Lautan Teduh. dan Laut Arafura sudah mencapai tingkat sedang sampai dengan tinggi.

Informasi cucut botol yang berkaitan dengan jenis yang tertangkap di perairan Indonesia, aspek biologi dan perikanan relatif sedikit bahkan boleh dikatakan belum ada yang melakukan penelitian secara khusus. Tulisan ini diharapkan dapat digunakan sebagai informasi dasar dalam melakukan kegiatan penelitian lebih lanjut.

\section{SPESIFIKASI PANCING RAWAI DASAR}

Di tempat pendaratan ikan Kedonganan-Bali, alat tangkap pancing rawai dasar (bottom long line) merupakan alat tangkap yang ditujukan untuk menangkap jenis cucut botol (Squalidae). Namun, di beberapa tempat pendaratan ikan seperti di Tanjung Luar-Lombok Timur, dan di Cilacap jenis cucut botol yang tertangkap dengan alat tangkap pancing rawai dasar dianggap sebagai hasil tangkapan sampingan. Meskipun demikian, dilihat dari spesifikasi alat tangkap tersebut tidak ada perbedaan di beberapa daerah. Spesifikasi alat tangkap rawai cucut botol terdiri atas seutas tali utama (main line). Tidak dibagi dalam keranjang-keranjang. Pada ke-2 ujung tali utama dipasang tali pelampung yang panjang disesuaikan dengan kedalaman perairan. Pada tali 
utama ini dipasang tali-tali cabang (branch line) yang jumlah mencapai 300 sampai dengan 600 buah. Mata pancing yang digunakan No.4. Sedangkan kapal yang digunakan pada umumnya berukuran 10 sampai dengan 20 GT dengan mesin berkekuatan 45 sampai dengan $60 \mathrm{HP}$. Lama operasi antara 7 sampai dengan 15 hari per trip. Spesifikasi pancing rawai dasar dapat dilihat pada Gambar 1

\section{MORFOLOGI DAN HABITAT}

Cucut botol (Squalus spp.) memiliki bentuk badan agak silindris. Di antara sirip dada dan sirip perut terdapat alur yang tidak terlampau nyata. Bentuk mulut bervariasi, ada yang pendek dan tumpul, ada yang panjang dan lancip, dan letak mulut di bagian ventral. Antara gigi rahang atas dan bawah bentuk sama atau berbeda. Terdapat celah insang yang letaknya dekat dengan sirip dada. Mempunyai 2 sirip punggung dan terdapat duri keras pada sirip punggungnya. Tidak mempunyai sirip dubur, bentuk sirip ekor bervariasi dan kuat. Pada umumnya berwarna abu-abu sampai dengan kehitaman.

Kebanyakan jenis ini hidup di perairan dengan kedalaman sekitar $50 \mathrm{~m}$ atau lebih, pada kondisi air yang dingin dengan suhu antara 6 sampai dengan $11^{\circ} \mathrm{C}$ (Castro et al., 1999). Di Indonesia genus Squalus tertangkap di perairan Samudera Hindia pada kedalaman mulai dari 50 sampai dengan sekitar $400 \mathrm{~m}$ di daerah slope (paparan benua). Genus Centrophorus yang juga termasuk jenis cucut botol ditemukan pada kedalaman perairan mulai dari 100 sampai dengan lebih dari $2.000 \mathrm{~m}$ (Anonim, 2003). Menurut Compagno (1984), pada umumnya di laut Artik sampai dengan Subantartik sebagian besar cucut botol dijumpai di dekat perairan dasar dengan kedalaman sekitar $3.675 \mathrm{~m}$ bahkan genus Centrophorus tertangkap pada kedalaman lebih dari $6.000 \mathrm{~m}$

Beberapa jenis cucut botol yang tertangkap dengan pancing rawai dasar disajikan di Samudera Hindia pada Gambar 2

\section{NISBAH KELAMIN}

Nisbah kelamin cucut botol yang merupakan gabungan dari beberapa spesies tersebut di atas dari 3 lokasi pendaratan ikan (Cilacap, Kedonganan, Bali, dan Tanjung Luar) menunjukan antara jenis jantan dan betina 35:65\% (Gambar 3).

Hal ini, memberikan indikasi bahwa jumlah cucut botol jenis betina lebih banyak tertangkap di perairan Samudera Hindia. Apabila hasil tangkapan cucut botol pada nilai perbandingan kelamin jantan dan betina tersebut dapat dipertahankan atau paling tidak jumlah jantan selalu lebih rendah dari jumiah betina, maka rekrutmen spesies ini akan berlangsung dengan baik sehingga populasi dapat stabil. Hal ini, akan mendukung kelangsungan populasi cucut karena sifat yang berumur panjang, reproduksi lama, dan jumlah embrio yang dihasilkan relatif sedikit yaitu antara 2 sampai dengan 4 embrio per ekor. Sebagai contoh untuk spesies Squalus acanthias mempunyai kematangan kelamin (mature) paling muda dicapai pada umur 24 tahun dengan kisaran panjang antara 93,4 sampai dengan $94,4 \mathrm{~cm}$, pada umur paling tua yaitu 62 tahun bahkan tidak mengalami kematangan kelamin (immature) (Mark \& Gordon, 1993). Selanjutnya, Ketchen (1975) menduga rata-rata kematangan kelamin betina cucut botol dicapai pada umur 34 tahun. Kematangan kelamin ikan pada dasarnya dipengaruhi oleh beberapa faktor

Menurut Saunder \& Gordon (1993) bahwa stres lingkungan seperti perubahan ketersediaan makanan menyebabkan pertumbuhan lebih lambat untuk populasi cucut yang matang kelamin pada ukuran lebih kecil. Sebaliknya, pertumbuhan lebih cepat pada populasi cucut dengan matang kelamin yang berukuran lebih besar. Ini berarti terdapat hubungan erat antara faktor lingkungan dan ukuran tubuh pada proses pertumbuhan terhadap cucut yang mengalami kematangan kelamin. Bonham et al. (1949) menduga di perairan Lautan Pasifik bagian utara $50 \%$ matang kelamin cucut botol betina dicapai pada umur antara 20 sampai dengan 34 tahun.

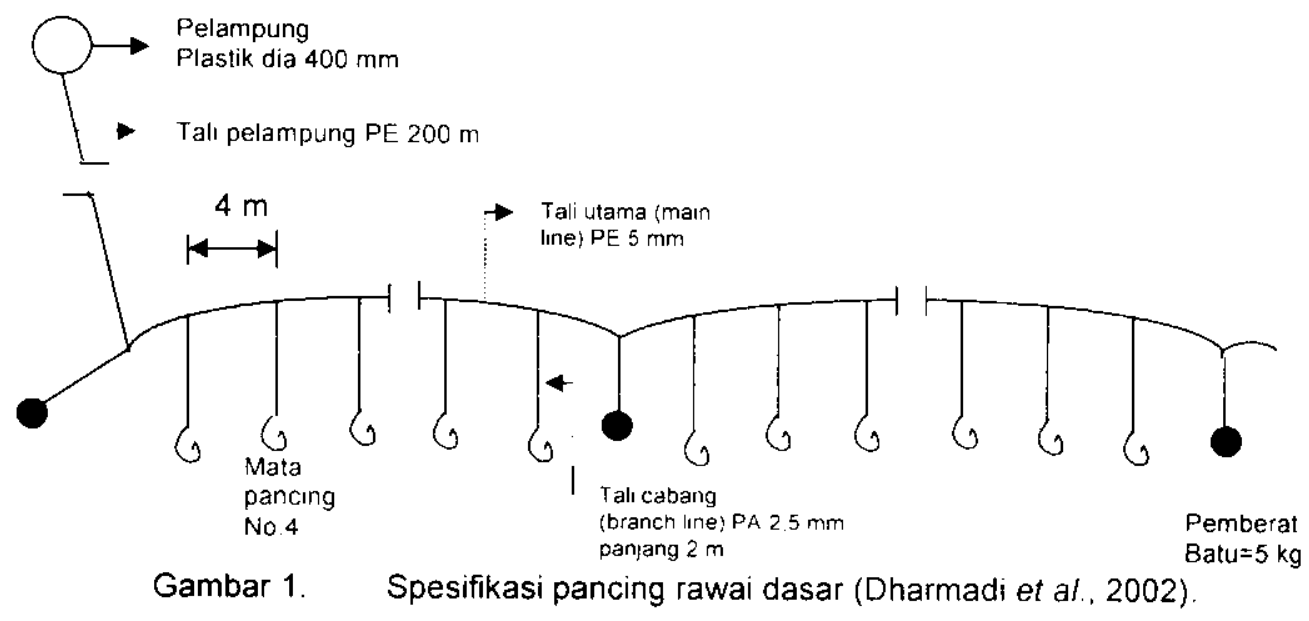




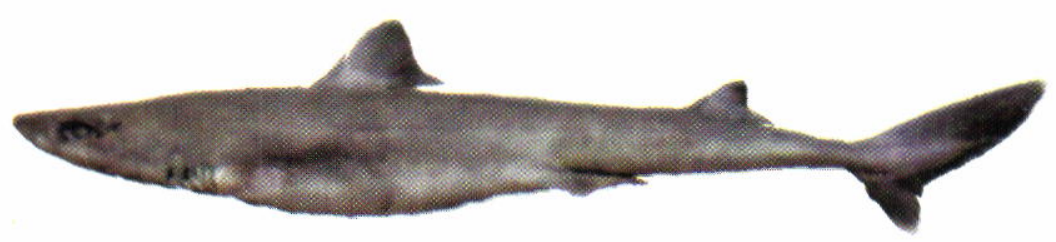

Squalus sp.1.

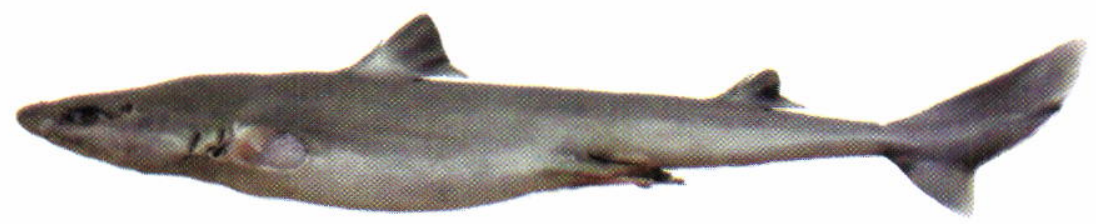

Squalus sp. 1b

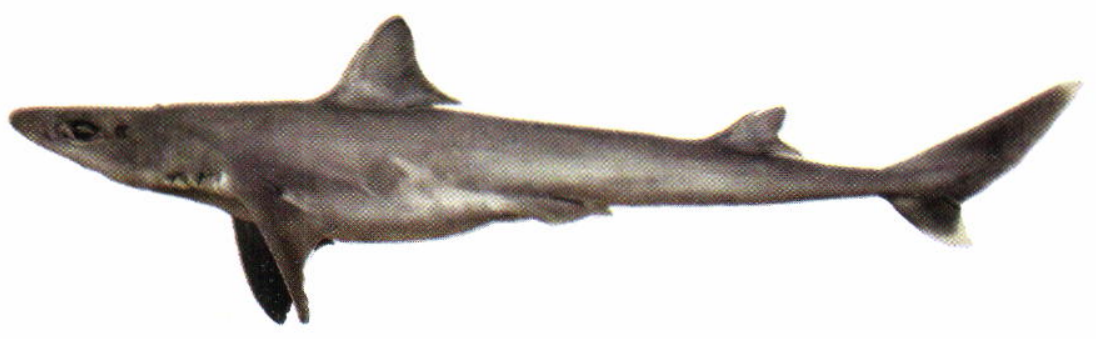

Squalus sp. 2.

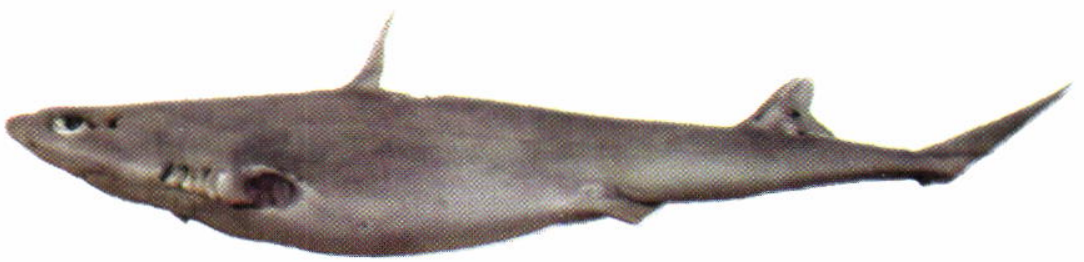

Squalus sp. 2 b.

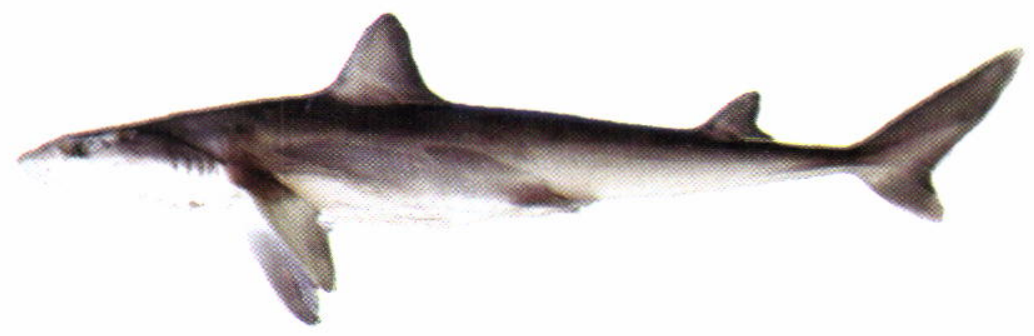

Squalus sp. $2 \mathrm{c}$.

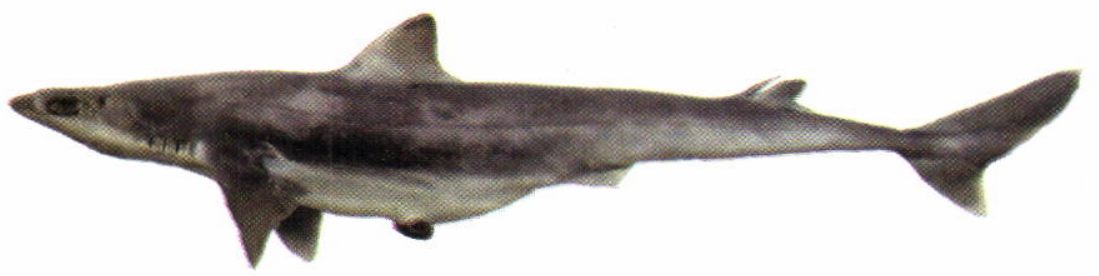

Squalus sp.3. 


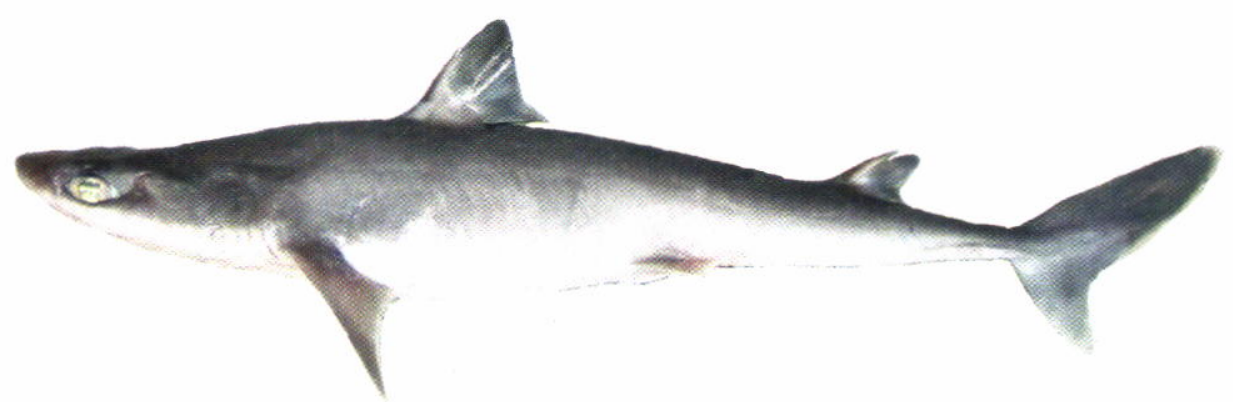

Squalus sp.3b

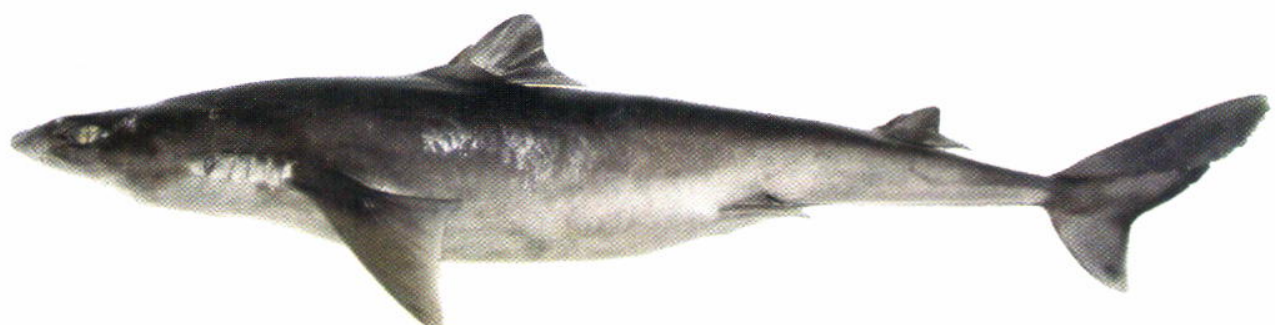

Squalus sp.4.

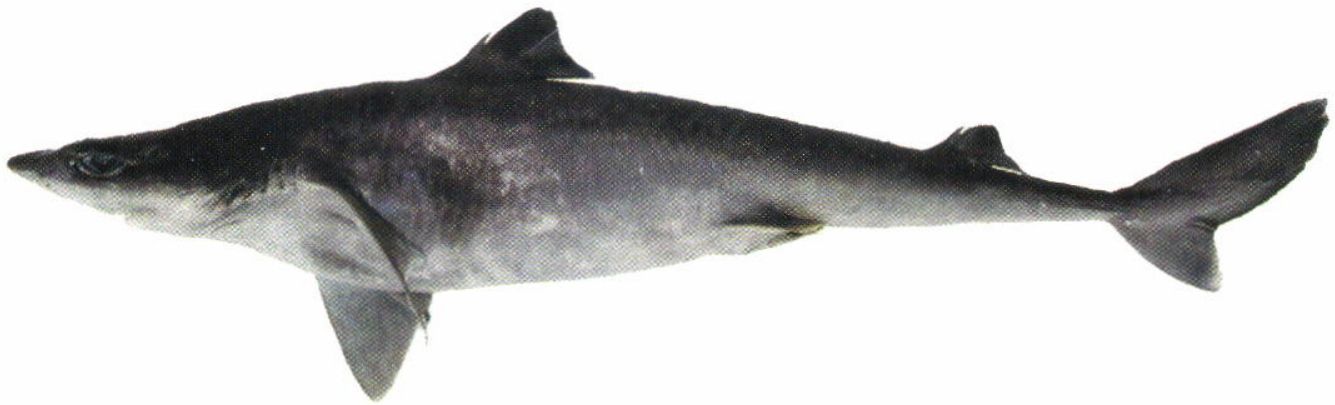

Squalus sp.4b.

Gambar 2. Beberapa jenis cucut botol yang tertangkap dengan rawai dasar di Samudera Hindia.

\section{KONDISI KLASPER}

Tingkat kematangan jenis kelamin jantan dapat dibedakan berdasarkan pada keadaan klasper yang terbagi dalam 3 tingkatan yaitu 1) klasper yang belum berisi atau belum mengandung kapur (not calsification), di mana ukuran klasper relatif kecil dan bila ditekan terasa lunak; 2) klasper yang telah berisi sebagian zat kapur (not full calsification), di mana klasper berukuran sedang dan belum penuh

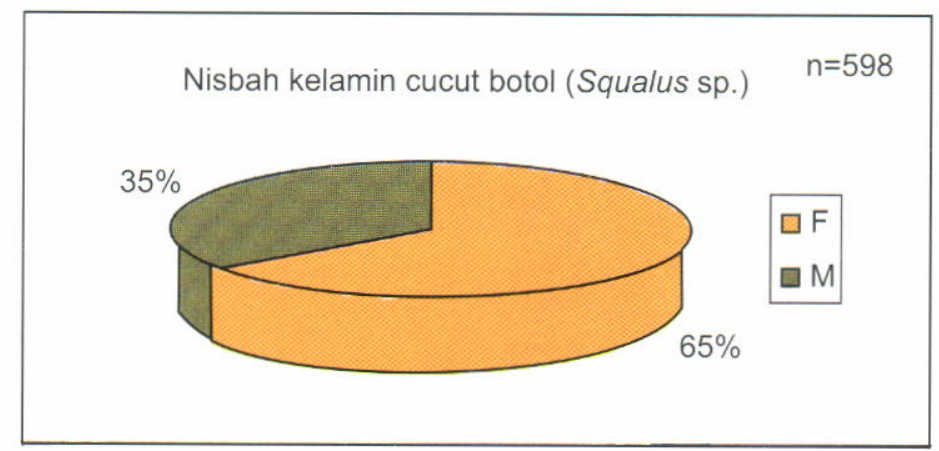

Gambar 3. Nisbah kelamin cucut botol.

mengeras; dan 3) klasper yang telah penuh berisi zat kapur (full calsification), di mana seluruh bagian klasper dari pangkal sampai dengan ujung klasper dalam kondisi mengeras dan berukuran lebih besar (Dharmadi et al., 2003).

Selama pengamatan di lapangan klasper cucut botol yang dijumpai sebagian besar menunjukkan kondisi full clasper. Kondisi klasper seperti ini sebagian besar dijumpai pada bulan Juni, di mana 
ukuran klasper pada periode tersebut lebih panjang dan dalam kondisi mengeras dibanding bulan Maret dan Oktober. Besar kecil ukuran klasper dapat menggambarkan suatu dugaan musim pemijahan. Klasper cucut botol yang berukuran besar dan dalam kondisi mengeras banyak dijumpai pada bulan Juni. Hasil pengamatan di lapangan pada periode tersebut banyak dijumpai klasper dalam kondisi mengeras atau terjadi kematangan alat kelamin jantan dari cucut botol dan bersamaan dengan waktu tersebut juga dijumpai embrio pada cucut botol betina. Klasper pada cucut terdapat 2 yaitu di bagian kiri dan di bagian kanan. Mekanisme terjadi proses kopulasi atau perkawinan antara cucut jantan dan betina dijelaskan oleh Dodd et al. (1982) yaitu sebagai berikut klasper bagian kiri akan bergerak menyilang ke arah klasper bagian kanan sampai dengan membentuk sudut $90^{\circ}$, kemudian klasper kiri dimasukkan ke dalam kloaka betina, sedangkan klasper bagian kanan tetap pada posisi lurus dan normal. Sementara itu, cucut betina hanya bereaksi dengan memejamkan ke-2 mata. Setelah selama 20 menit pasangan cucut tersebut badan seolah-olah tidak bergerak tetapi kepala bergerak sampai dengan mencapai setengah lingkaran atau $180^{\circ}$

\section{KESIMPULAN}

Di perairan Samudera Hindia terdapat 9 jenis cucut botol yang teridentifikasi sejak tahun 2001 sampai dengan 2005. Cucut botol tertangkap dengan pancing rawai dasar pada kedalaman antara 100 sampai dengan $200 \mathrm{~m}$. Perbandingan nisbah kelamin cucut botol antara jantan dan betina $65: 35 \%$. Sedangkan tingkat kematangan kelamin jantan sebagian besar terdapat pada kondisi di mana klasper dalam keadaan penuh berisi zat kapur (Full calsification).

\section{DAFTAR PUSTAKA}

Anonim. 2003. Artisanal shark and ray fisheries in East Indonesia: Their socio, economic, and fishery characteristics and relationship to Australian resources. Second Annual Report. FIS 2000/062. 73 p

Bonham, K., F. B. Sanford, W. Clegg, \& G. C. Bucher 1949. Biological and vitamin A studies of dogfish landed in the State of Washington (Squalus suckleyi). Wash. Dept.Fish. Bio.Bull. 49A: 83-113.

Castro, J. I., C. M. Woodley, \& R. L. Brudek. 1999. A Preliminary evolution of the status of shark species. National Oceanographic and Atmospheric Administration. National Marine Fisheries Service Southeast Fisheries Science
Center Miami. Florida. USA. FAO. Fisheries Technical Paper No.380

Compagno, L. J. V. 1984. FAO species catalogue. Vol.4. Sharks of the world. An annotated and illustrated catalogue of sharks species known to date. Part 1. Hexanchiformes to Lamniformes. FAO Fish. Synop. (125) Vol.4. Pt 1: 249 p.

Compagno, L. J. V. 1990. Alternative life history style of cartilaginous fishes in time and space. Environmental Biology of Fishes 28: 33-75. 1990. Kluwer Academic Publisher. Netherlands.

Dharmadi, A. Agustinus, \& J. Widodo. 2002. Aspek biologi dan penangkapan cucut di Cilacap. Jurnal Penelitian Perikanan Indonesia. Edisi Sumber Daya dan Penangkapan. Badan Riset Kelautan dan Perikanan. Departemen Kelautan dan Perikanan. Vol. 8 No.1.

Dharmadi \& Fahmi. 2003. Fisheries characteristics of artisanal sharks and rays in Indonesia waters Papaers International Seminar on Marine and Fisheries IMFS. 15-16 December 2003. AMFRMMAF. p. $122-129$

Dharmadi, Maria M. W., \& Anung W. 2003. Morfologi, habitat, dan biologi cucut genus Alopias. Warta Penelitian Indonesia. Edisi Sumber Daya dan Penangkapan. Vol.9 No.5.2003. Hal: 20-25

Dodd J. M., M. H. Dodd, \& R. T. Duggan. 1982 Control of reproduction in elasmobranch fishes. Crom Helm London and Canberra

Ketchen, K. S. 1975. Age and growth of dogfish (Squalus Acanthias) in British Colimbia waters Journal Fisheries Resources Board Canada. 32 43-59

Mark, W. S. \& Gordon A. M. 1993. Age and length at maturity of the female spiny dogfish, Squalus acanthias, in the Strait of Georgia, British Columbia, Canada. Environmental Biology of Fishes. 38: 49-57. Kluwer Academic Publishers p. $49-57$.

Saunders, M. W. \& Gordon A. M. 1993. Age and length a maturity of the female spiny dogfish, Squalus acanthias, in the Strait of Georgia, British Columbia, Canada. Environmental Biology of Fishes 38: 49-57. 1993. Kluwer Academic Publishers. Netherlands.

Widodo, J. 2002. Pengantar pengkajian stok ikan Pusat Riset Perikanan Tangkap. Badan Riset Kelautan dan Perikanan. Departemen Kelautan dan Perikanan. 16 hal. 
